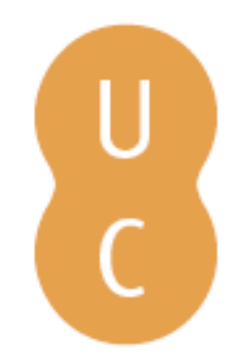

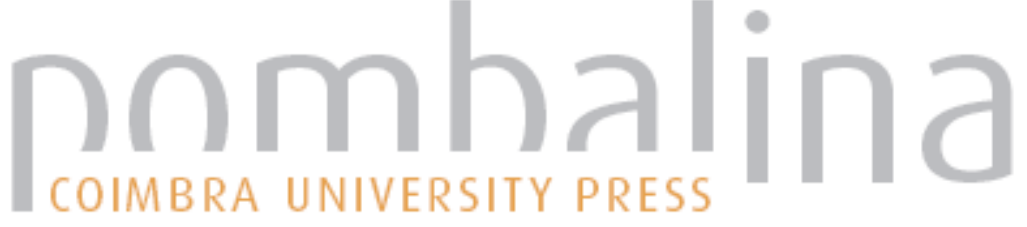

\section{A poética do desporto em Maurice Genevoix}

\author{
Autor(es): $\quad$ Fernandes, Ana
}

Publicado por: Imprensa da Universidade de Coimbra

URL

persistente: URI:http://hdl.handle.net/10316.2/38376

DOI: $\quad$ DOI:http://dx.doi.org/10.14195/978-989-26-0371-1_14

Accessed : $\quad$ 26-Apr-2023 14:56:28

A navegação consulta e descarregamento dos títulos inseridos nas Bibliotecas Digitais UC Digitalis, UC Pombalina e UC Impactum, pressupõem a aceitação plena e sem reservas dos Termos e Condições de Uso destas Bibliotecas Digitais, disponíveis em https://digitalis.uc.pt/pt-pt/termos.

Conforme exposto nos referidos Termos e Condições de Uso, o descarregamento de títulos de acesso restrito requer uma licença válida de autorização devendo o utilizador aceder ao(s) documento(s) a partir de um endereço de IP da instituição detentora da supramencionada licença.

Ao utilizador é apenas permitido o descarregamento para uso pessoal, pelo que o emprego do(s) título(s) descarregado(s) para outro fim, designadamente comercial, carece de autorização do respetivo autor ou editor da obra.

Na medida em que todas as obras da UC Digitalis se encontram protegidas pelo Código do Direito de Autor e Direitos Conexos e demais legislação aplicável, toda a cópia, parcial ou total, deste documento, nos casos em que é legalmente admitida, deverá conter ou fazer-se acompanhar por este aviso.

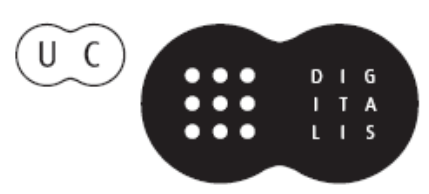


FRANCISCO DE OLIVEIRA

Coordenação

Ospírito Olímpico

no

novo milénio 


\section{A POÉTICA DO DESPORTO EM MAURICE GENEVOIX}

Ana Fernandes Universidade Católica

Buscar na literatura francesa autores ou obras em que o desporto tivesse algum peso não foi tarefa fácil, muito menos na época que mais tenho estudado, o século XVIII. No entanto, a partir do século XIX e sobretudo no século $X X$, este tema encontra vários adeptos e até se vê nascer uma profícua literatura desportiva.

Maurice Genevoix foi o autor escolhido pela beleza do texto que nos ofereceu, primeiro em 1925 com Euthymos, vainqueur olympique, texto que foi aumentado e viu uma segunda publicação, em 1960, com a mudança de título para Vaincre à Olympie. De um a outro, permanece a mesma ideia de vitória nos jogos olímpicos, embora o segundo título seja mais impessoal.

A obra divide-se em três livros, mas todos convergem para uma concentração no herói Euthymos de Locres, e de todos sobressai a beleza física e a comparação entre o homem mortal e os deuses eternos. É daqui que resulta aquilo a que chamámos a "poética do desporto" e, poderíamos acrescentar, do corpo.

Tratar a "poética" de um texto é tentar perceber a especificidade do discurso literário, a qual enriquece a nossa percepção de uma gama de harmónicas e de uma rede de significações em que o imaginário tem um lugar preponderante. Isto não quer dizer que a literatura só profira mentiras, ao construir imagens arbitrárias e sem relações necessárias com o real, antes pelo contrário ela alimenta-se de referencialidade. A descrição e até a análise propriamente literárias são as únicas capazes de dar conta do real na sua totalidade. Ao lermos o texto de Maurice 
Genevoix, assistimos à emergência de um "espaço poético", no sentido primeiro do termo, isto é, um espaço criado pelo discurso literário, que comporta mais realidade que o próprio acontecimento ou o facto bruto que se passou no estádio. As imagens que a literatura utiliza, as "conotações" que ela liberta, as analogias que sugere, as impressões que traduz ou as evocações a que nos convida, são modos de nos despertar para uma visão dos factos, de motivar a nossa afectividade, a nossa sensibilidade, para todos os traços, cores, nuances, singularidades ou aproximações harmónicas, permitindo-nos assim melhor penetrar no "vivido" dos praticantes ou dos espectadores, que passaremos a estudar.

Um dos temas mais constantes da literatura desportiva, sobretudo no seu início, é o do tipo de beleza que a prática do desporto confere ao corpo do atleta. O conhecimento de si passa pelo reconhecimento do seu corpo. As teorias do desporto e da educação física oscilam entre a consideração do corpo como suporte ou simples instrumento que é preciso domesticar e aprender a manejar o melhor possível. Assim, podemos constatar que na obra que estudamos, Euthymos de Locres treina-se para os Jogos Olímpicos de forma sistemática e persistente: "Mais tant de durs travaux devaient avoir leur récompense. Maintenant le corps d'Euthymos s'était chargé de muscles larges, aux attaches sèches et déliées." (p.98). Qualquer aprendizagem desportiva deve revelar a personalidade do atleta, mas também constrangir o seu corpo para que a desordem da natureza dê lugar à harmonia da "cultura" física e à beleza: "A peine avait-il dix-neuf ans, mais il montrait sous la chlamyde l'apparence d'un homme fait; et, dès qu'il était nu, l'on sentait au premier quelle force terrible animait son corps de vivant" (p.98). Este treino, que combina o progresso da consciência do corpo com a aquisição de mecanismos ou de automatismos, é acompanhado pouco a pouco de um sentimento de libertação: Euthymos suivait l'alipte, comme lui délivré de son corps, ivre d'une liberté divine" (p.93). Apropriar-se do seu corpo, ser o seu corpo, consiste em não depositar nele, como se se tratasse de uma entidade distinta, a responsabilidade de um comportamento em que não quer reconhecer-se, mas, pelo contrário, em conhecê-lo e em tornar-se capaz de controlar cada vez melhor as suas reaç̧ões e os seus movimentos: "Aussi bien que son maître, Euthymos savait à présent les places vulnérables du corps, celles qu'il faut chercher à frapper" (p.99). 
Perdendo o seu peso de instrumento ou de objecto, o corpo parece aligeirar-se. Por força de habitar plenamente o seu corpo e de ser o seu corpo, o atleta, em estado de graça, acaba por perder a consciência de ter um corpo. Este estado supremo é atingido na realização perfeita de todas as suas virtualidades. Nesses instantes privilegiados em que se manifestam estes poderes, o corpo encontra-se sublimado, volatilizado, solúvel no ar: 'leurs corps planent, libérés de la dure pesanteur, emportés tous ensemble sur l'aile de la Vitesse divine. Ceux qui les voient planent avec eux" (p. 168).

O treino que permite que o desportista melhor se conheça, possibilita- Ihe responsabilizar-se pelo seu corpo. Este auto-conhecimento tem uma incidência evidente sobre o comportamento geral. A cultura física é também uma educação moral, que toca a disciplina de si e a vontade: "Et Euthymos, plein de respect, sentait la force de sa volonté, l'ardeur de son espérance" (p.87). A concentração não é senão substituir um estado de alma por um estado de corpo e, por isso mesmo, o atleta abstrai-se de tudo, da pátria de que tem de se afastar temporariamente, do seu passado mal conhecido, do amor por Cymothoé que o poderá fazer vacilar. O desporto consiste em delegar no corpo algumas das virtudes mais fortes da alma: a energia, a audácia, a paciência: 'Il le faisait courir sur les pentes les plus escarpées, traverser les fourrés d'épines, franchir d'un bond le lit des torrents. [...] II loua son élève de sa constance, de son courage" (p.97, 100). E são também eles os princípios de todo o atleta: "Fidèle à sa gloire passée en même temps qu'aux ordres des dieux, il chercherait, de ville en ville, les jeunes athlètes entre les mieux doués; et, les ayant trouvés, il cultiverait en eux les vertus qui donnent la victoire: la force, l'agilité, le caractère, et le désir de vaincre" (p. 121). É o espírito olímpico que se enuncia na procura em promover o desenvolvimento das qualidades físicas e morais do indivíduo.

Este culto do corpo gera beleza, fazendo- o aparentar-se assim à arte. Maurice Genevoix insiste então neste aspecto quando nos mostra um atleta que é comparado à estátua de um atleta olímpico: "Il avait les mêmes jambes longues,... la vigueur de son torse" (p.30). Na obra que estudamos, este tipo de comparação é frequente, e não é para admirar, pois, que o desporto seja tema evidente de inspiração dos escultores, e também não é por acaso que um dos capítulos de Vaincre à Olympie tem 
por título "Le sculpteur", personagem que a dado momento afirma: malgré moi, tandis que de mes mains je modelais et animais l'argile, j'étais hanté par la forme virile, aux épaules larges, aux hanches étroites, aux bras musclés. [...] Tous, tant que nous sommes, sculpteurs, nous avons trop flâné dans les palestres. Toutes les visions dont brille notre mémoire sont d'athlètes nus dans le soleil." (p.87-88) - a imagem real serve assim de inspiração à arte e nesta se vai espelhar.

O olhar posto pelo homem sobre o seu próprio corpo modifica-se e - narrador que o transporta observa-o na sucessão dos seus movimentos com a minúcia de um anatomista. A antinomia suposta da tecnicidade e da "literariedade" encontra-se abolida pelo facto de que a menção aos músculos e às partes do corpo não é feita através de uma designação e, por isso mesmo, tal não confere de todo ao texto o ar de um curso de anatomia, mas participa, pelo contrário, com o ritmo, a escolha das imagens e das comparações, numa viva sinfonia: "Son buste, incliné sur le flanc, se soutenait sur son bras droit plié qui, du coude, appuyait sur le sol; son bras gauche s'allongeait, détendu, suivant la courbe de sa hanche et laissant sa main reposer, les doigts entrouverts à demi, sur sa cuisse aux muscles pesants" (p.94); "On les voit se plier sur eux-mêmes, le buste horizontal, un peu courbé comme un bel arc. Leur force, en ondes profondes, s'éveille, s'accumule, se durcit. Elle bande leurs jambes, elle crispe leurs orteils dans les rainures de brique chaude" (p. 168). O escritor provoca deliberadamente o leitor e quer incitá- lo a prestar atenção ao que o seu olhar habitualmente negligencia: as diferentes partes do corpo podem ser dotadas de expressão.

Mas o homem, na sua força e pujança adquire características de bestialidade. Mesmo se o dualismo homem/animal é fortemente contestado, em Maurice Genevoix as comparações surgem com certa frequência e o que é especificamente humano adquire características 200 animalescas: 'Ilsouffle bruyamment, il mugit. Frappe, Euthymos! C'est un buffle, $\quad$ Ekhékratidas, un buffle aveugle!" (p. 126); "Euthymos plus roidement qu'un bélier contre la porte d'une ville, a lancé son terrible poing droit" (P-| 89).

O que sobressai contudo do espectáculo corporal é a beleza evidenciada na sua nudez: “dès qu'il était nu, l'on sentait au premier regard quelle force terrible animait son corps de vivant. Je le revois en ce temps, 
Sostratos. Et j'en puis témoigner par le Soleil qui éclaire toutes choses, il était beau" (p.98). Ou então quando na nudez homens e estátuas se confundem: 'Oui, Sostratos, c'est bien elle, la table des olympionikes. Colotès a ciselé sur ses quatre côtés limage des dieux et des athlètes. L'ivoire est blanc sur le champ d'or. Les pâles nudités en prennent un éclat rayonnant, comme au soleil du stade les corps vivants des jeunes hommes" (p. 148). Em Vaincre à Olympie, o leitor reencontra a nudez dos "primitivos", de que os Gregos conservam o uso para a sua ginástica - como o mostra a etimologiaO.

Não é lugar comum a beleza transcender o tempo? Em todo o caso a sua constância testemunha a verdade da primeira impressão. Esta verdade depende ela própria da felicidade com que o escritor traduz a emoção. Em Maurice Genevoix existe um exemplo singular. Quando evoca a corrida antiga de Olímpia, eis que de repente qualquer noção do tempo é abolida: "H n'y a jamais eu que le rayonnement du soleil, la piste fauve" (p. 168). Curioso emprego do perfectum que designa aqui não o resultado presente de uma acção passada, mas justamente a perfeição desse instante, que o situa fora do tempo, factor de evolução e de aniquilamento. O perfectum utilizado aqui por Maurice Genevoix alia-se a um dos valores de emprego do presente que ultrapassa infinitamente tanto o passado como o futuro e sugere a natureza intemporal deste instante que, contudo, "objectivamente", só figura como um ponto muito ténue na cadeia temporal. Esta beleza tem o carácter evanescente de um sonho, e contudo evoca-se frequentemente a estatuária a seu propósito, o das artes que assegura mais a perenidade da obra.

O tempo também se pode suspender na corrida a pé, é o que nos sugere precisamente Maurice Genevoix quando afirma: "//s courent et semblent suspendus. Les corps planent, libérés de la dure pesanteur, emportés tous ensemble sur l'aile de la Vitesse divine" (p. 168).

As comparações são uma constante no livro, e não podemos deixar de focar uma certa consagração da graça, a qual transporta o homem para uma esfera superior que o faz esquecer o banal da sua existência

(') Do grego gymnos : nu. que levou a "ginástica" e ao facto de que os atletas apresentavam- se nus para realizar os seus exercícios. 
quotidiana, e sugere uma promoção da natureza e da condição humanas que inspiram o poeta. Em Maurice Genevoix, a graça remete para a ideia grega de que o que os homens partilham com os deuses, não é unicamente a inteligência, mas também a beleza, fazendo interferir sabiamente a maioria dos temas uns com os outros: courent, nus dans le soleil. Des flocons de poussière éclosent sous leurs talons. [...] Ceux qui les voient planent avec eux: tous les maux, les misères, les laideurs, les voici soudain oubliés. II n'y a jamais eu que le rayonnement du soleil, la piste fauve et l'allongement des corps rapides, les taches d'ombre qui naissent et s'effacent au creux des jarrets vigoureux, les talons qui battent l'air en arrière, qui le refoulent et s'y appuient pour aider l'élan des poitrines, tendues, tendues, poussées en avant par les coeurs, et le mouvement des bras qui redisent dans la lumière l'envolée des jambes admirables. Plus vite! On voudrait qu'ils arrivent et que leur course n'ait point de fin. La foule palpite, halète, ravie au-dessus d'elle-même par le spectacle de cette beauté brûlante, qui s'emblée touche à son apogée, et s'y maintient, miraculeusement" (p. 168- 169). Página plena de vigor e de dinamismo, mas em que, ao mesmo tempo, se vê o movimento evoluir para uma frequência imóvel. Sente-se a vontade de traduzir a impressão de que a sucessão destes instantes parece tender para a eternidade, assim como a sucessão dos gestos rápidos se resolve numa espécie de suspensão sugerida pelo verbo "planer" que sugere a suspensão temporal a que já nos referimos. Este esforço violento transmuta-se em graça, e mesmo se esta alquímica operação é sobretudo fruto da transposição literária, é preciso que o autor tenha percebido e sentido assim a corrida do estádio para a ter querido traduzir e "transmitir" desta forma. A força, a violência, o esforço existem, é certo, mas não nos apercebemos do seu carácter penoso: o que predomina é a impressão catártica que se apodera dos corações. Espaço e tempo são abolidos. O estádio olímpico transfigura-

202 se de repente: eis- nos transportados para a Olímpia inacessível ao tédio: 'L'enchantement des Jeux a saisi les pèlerins d'Olympie. Pendant cinq jours, ils seront ivres. Leur vie est une fontaine de joie qui ne saurait jamais tarir" (p. 169). A "graça" surge em toda a sua força, tanto no seu sentido puramente estético, como na sua acepção mística e religiosa quando os atletas são comparados a deuses: "Et Euthymos, dans ses propres veines, sentait couler le sang d'un dieu" (p.94). 
Qual a impressão geral que nos fica deste romance de Maurice Genevoix? Em Vaincre à Olympie, o autor oferece-nos o romance dos primeiros jogos olímpicos, remontando até à pureza das fontes. "Un à un, les athlètes s'avancent lls jurent devant Zeus d'être loyaux, de craindre les dieux...". Euthymos de Locres veio para afrontar os melhores pugilistas, "boire à longs traits le vin grisant de la victoire" e colocar na sua cabeça a coroa de oliveira sagrada, medalha de ouro da época e que reveste uma simbologia muito forte de fecundidade, paz, força, vitória e recompensa.

O autor faz-nos assistir como espectadores privilegiados aos Jogos de Olímpia, sacrificar aos deuses, participar no triunfo de Euthymos, que só se torna possível porque o herói se abstrai de qualquer relação humana que o possa distrair e comprometer na sua vitória.

Vaincre à Olympie é o romance em que o Eu se suplanta: triunfo do estádio, triunfo da juventude, sob o céu helénico, num mundo povoado de deuses. Este mundo grego, onde a nossa civilização encontra as suas mais nobres origens, é aqui apresentado com toda a vivacidade. O livro magistral de Maurice Genevoix leva-nos de forma feliz até ao movimento, até ao calor da sua própria vida, narrando a criação do corpo paralelamente à descoberta do exercício físico.

\section{BIBLIOGRAFIA}

GENEVOIX, Maurice, 1960, Vaincreà Olympie, Paris, Le Livre Contemporain.

CHARRETON, Pierre, 1990, Le Sport, I'Ascèse, le Plaisir, Saint-Etienne, Centre Interdisciplinaire d'Étude et de Recherche sur l'Expression Contemporaine (CIEREC). 